University of Nebraska - Lincoln

DigitalCommons@University of Nebraska - Lincoln

\title{
Kernel Morphology Variation in a Population Derived from a Soft by Hard Wheat Cross and Associations with End-Use Quality Traits
}

\author{
Christine J. Bergman \\ USDA. Agricultural Research Service \\ Daisy G. Gualberto \\ USDA-ARS \\ Kimberly A. Garland-Campbell \\ Ohio State University, kim.garland-campbell@usda.gov \\ Mark E. Sorrells \\ Cornell University \\ Patrick L. Finney \\ USDA-ARS
}

Follow this and additional works at: https://digitalcommons.unl.edu/usdaarsfacpub

Part of the Agricultural Science Commons

Bergman, Christine J.; Gualberto, Daisy G.; Garland-Campbell, Kimberly A.; Sorrells, Mark E.; and Finney, Patrick L., "Kernel Morphology Variation in a Population Derived from a Soft by Hard Wheat Cross and Associations with End-Use Quality Traits" (2000). Publications from USDA-ARS / UNL Faculty. 407. https://digitalcommons.unl.edu/usdaarsfacpub/407

This Article is brought to you for free and open access by the U.S. Department of Agriculture: Agricultural Research Service, Lincoln, Nebraska at DigitalCommons@University of Nebraska - Lincoln. It has been accepted for inclusion in Publications from USDA-ARS / UNL Faculty by an authorized administrator of DigitalCommons@University of Nebraska - Lincoln. 


\title{
KERNEL MORPHOLOGY VARIATION IN A POPULATION DERIVED FROM A SOFT BY HARD WHEAT CROSS AND ASSOCIATIONS WITH END-USE QUALITY TRAITS ${ }^{1}$
}

\author{
CHRISTINE J. BERGMAN ${ }^{2,6}$, DAISY G. GUALBERTO ${ }^{3}$, KIMBERLY G. \\ CAMPBELL ${ }^{4}$, MARK E. SORRELLS $S^{5}$ and PATRICK L. FINNEY ${ }^{3}$ \\ ${ }^{2}$ USDA, Agricultural Research Service \\ Rice Research Unit \\ I509 Aggie Drive \\ Beaumont, $T X 77713$ \\ ${ }^{3}$ USDA, ARS \\ Soft Wheat Quality Laboratory \\ 1680 Madison Ave. \\ Wooster, OH 4469I \\ Ohio State University \\ Department of Horticulture and Crop Science \\ Ohio Agricultural Research and Development Center \\ 1680 Madison Ave. \\ Wooster, OH 44691 \\ ${ }^{5}$ Department of Plant Breeding and Biometry \\ 252 Emerson Hall \\ Cornell University \\ Ithaca, NY 14853
}

Accepted for Publication January 5, 2000

\begin{abstract}
Physical attributes, including kernel morphology, are used to grade wheat, and indicate wheat milling and baking quality (MBQ). Using a recombinant inbred population derived from a soft by hard wheat cross, this study quantified kernel traits' sources of variation, studied their heritability, and relationships between morphological and $M B Q$ traits. Transgressive segregation occurred for all traits. Thousand-kernel weight (TKW) and kernel texture (NIR-T) were primarily

'Mention of a trademark or proprietary product does not constitute a guarantee or warranty of a product by the US Department of Agriculture, and does not imply its approval to the exclusion of other products that also can be suitable.

${ }^{6}$ Corresponding author. Phone: (409) 752-5221; FAX: (409) 752-5720; E-mail: c-bergman@tamu.edu


influenced by genotype and test weight (TW) mainly by year. NIR-T had the highest heritability. Low genetic correlation (GCOR) between kernel length (LEN) and width (WID) suggest independent inheritance. NIR-T and LEN, or WID, showed low GCOR. Thus, it is genetically feasible to produce cultivars with any kernel texture and LEN, or WID, combination. No GCOR was found between TW and flour milling yield (FY), TKW, NIR-T or kernel morphology. GCOR showed that harder wheats had greater FY. Traits' low correlations call for studies clarifying the efficacy of using kernel traits in wheat classification or end-use quality prediction.

\section{INTRODUCTION}

In the United States (US), wheat is segregated based on kernel texture (hard or soft). The importance of kernel texture to the milling and baking industry is due to its association with flour water affinity, damaged starch level in flour, and soft wheat product texture (Evers and Stevens 1985; Gaines et al. 1992a, b). Besides texture, kernel morphological characteristics are also important. For example, the US Grain Inspection, Packers, and Stockyards Administration (GIPSA) uses kernel color, shape and length, and the germ, crease and brush shapes to place wheat into textural classes (GIPSA 1997). The focus on these characteristics stems from the historical US trend that hard wheat kernels are long, narrow and translucent while soft wheat kernels are short, round and opaque. Recently, interested in combining desired characteristics from each, wheat breeders have hybridized soft and hard wheats. Doing so may reduce the relationships between wheat class and kernel morphology, thereby placing the GIPSA classification system at risk for errors.

Variation in kernel morphology may impact aspects of wheat milling and baking quality (MBQ). However, minimal literature is available addressing this issue. Food industry personnel have voiced concerns on the potential impact that variation in kernel size may have on wheat milling and baking quality MBQ. For example, breakfast cereal companies have suggested that different sized kernels used in processes that require the soaking of whole kernels have differences in the rate of water uptake. Pomeranz and Afework (1984) reported that kernel grinding time and flour particle size, both measures of kernel texture, increased as kernel size decreased. That trend was greater in shriveled than in plump kernels. Marshall et al. (1986) reported that kernel size (weight or volume) correlated with flour milling yield (FY) within hard wheat cultivars but not across them. By utilizing kernel trait measurements as measured by image analysis, Berman et al. (1996) were able to explain $66 \%$ of the variation in FY. As a result, those authors suggested that kernel traits could be used as a predictor of FY. Confirmatory evidence of the reported correlations between kernel dimensions and FY and other end-use quality traits is needed prior to breeders and millers beginning to use those 
measurements as predictors of any aspect of wheat quality.

Test weight (TW) has been reported by some to be a good predictor of FY, while others have documented that measurement may not be reliable for soft or hard wheat predictions (Ghaderi and Everson 1971; Hook 1984; Finney and Bergman 1994; Schuler et al. 1995). Since no other practical method has been found to supplement or replace TW in the wheat current grading system, it continues to be studied and wheat breeders continue to have a focus on producing genotypes with high TW. Accordingly, there is a need to clarify the relationships between TW and kernel morphology and end-use quality traits.

A clear understanding of the genetics controlling kernel morphology traits and their associations with end-use quality traits requires that studies be designed taking in consideration genetic and environmental effects. Recombinant inbred lines (RIL) are ideal for such studies. Studies examining the genetics underlying various end-use quality traits using RILs developed from crosses between hard and soft wheats have been performed (Davis et al. 1960; Briggle et al. 1968; Lofgren et al. 1968; Bergman et al. 1998). None of those studies, however, examined the genetics controlling kernel morphology or their associations with end-use quality.

The objectives of this study were: (1) to determine the effects of genotype, environment, and genotype by environment interactions on kernel morphology traits in a population derived from a soft by hard wheat cross, and (2) to examine the relationships between those traits and various MBQ traits.

\section{MATERIALS AND METHODS}

The population consisted of $78 \mathrm{~F}_{5}$-derived RILs developed by single-seed descent (Anderson et al. 1993) from a cross of the soft white wheat NY6432-18 (NY18) and the hard white wheat Clark's Cream (CC). The population was grown at two locations (two field replications per location) in 1992, 1993 and 1994 as described by Bergman et al. (1998). In 1992 and 1993, due to the small quantity of grain available, the samples were hand cleaned to remove shriveled and broken kernels, whereas in 1994, they were air aspirated.

Test weight (TW) was determined by the AACC method 55-10 (AACC 1995). Thousand kernel weight (TKW) was determined by counting and obtaining the weight of the entire grain sample using an electronic seed counter, (Model 701-10, Davis Tool and Engineering, Inc., Montgomery, IL). Kernel texture (NIR-T), often called "hardness", was determined using a Technicon Infra-analyzer (Technicon Corp., Tarrytown, NY) as described in method 39-70A (AACC 1995). The above mentioned traits were determined, in duplicate. TW and TKW were measured using the 1993 and 1994 samples and NIR-T was determined using samples from all three years.

Digital image analyses of grain samples grown in 1993 and 1994 were 
performed using a black and white CCTV camera (Model JE7262, Javelin Electronics, Los Angeles, CA) and a 1:18 25-mm TV lens (Sony Corp., Japan) and MOCHA image analysis software version 1.1 (Jandel Scientific, San Rafael, CA). Samples were illuminated with white light in 1993. Red lights were used in 1994 samples to provide better contrast between the kernel and the background surface and to reduce experimental error. Calibration was performed such that the light reflected from a Kodak gray card (Eastman Kodak, Rochester, NY) was equal to 26 and the black card equal to 121 on a 256 black to white scale. The threshold used to differentiate the kernel from the black background was 110 on the gray scale in 1993 samples, and 70 on the gray scale in 1994 samples. Each pixel was calculated to be equivalent to $0.38 \mathrm{~mm}$.

The number of kernels to be measured per sample was determined according to DeKoeyer et al. (1993). A sample size of $50 \mathrm{kernels}$ was deemed adequate. Kernel shape factor (SF) was calculated for individual kernels as $4 \pi \times$ (area)/perimeter ${ }^{2}$. Density factor (DF) was determined on a sample basis as $\mathrm{TKW} /$ mean kernel area.

Descriptive statistics were determined for all variables using the UNIVARIATE procedure of SAS with the NORMAL option (SAS Institute 1988). For each trait, the fit to a normal distribution was checked using the Shapiro Wilk W statistics and full normal plots. Various transformations were tried to improve data normality. None of the traits were substantially improved through those efforts, thus transformed variables were not used.

The effects of location, plot, genotype, and their interactions on the various kernel traits were determined using the GLM procedure of SAS. The proportion of variance attributed to those sources was quantified by equating expected with actual mean squares. All effects were considered to be random and significance was examined using F-tests appropriate for the model. Error variances among locations were not homogenous for TW, TKW or NIR-T. For those traits, the analysis of variance combined over locations was weighted by the inverse of the within-location error variance. Weighted genotype means were obtained. Because of the differences in illumination for 1993 and 1994, values for the digital image analysis traits were standardized by subtracting the mean and dividing by the standard error from the analysis of variance within each location. Rank correlation was used to examine the TW, TKW and NIR-T genotype by environment interactions. Differences among ranks over environments were tested using the Kruskal-Wallis k-sample test (SAS Institute 1988).

Least square entry means obtained from the combined analyses were compared with parental means in order to determine if transgressive segregation existed for each trait $(p<0.05)$. Genetic correlations $\left(r_{g}\right)$ were calculated by equating expected mean cross products with actual mean cross products, obtained from multivariate analysis, using the MANOVA option of the SAS GLM procedure (Falconer 1989). Partial correlation and multiple regression analyses were also utilized. However, 
the results are not presented as they were of no consequence. Heritabilities and their $95 \%$ confidence limits were calculated for each trait on an entry mean basis (Knapp et al. 1985).

\section{RESULTS AND DISCUSSION}

Most of the kernel trait distributions deviated only slightly from normality (Fig. 1, 2 and 3). NIR hardness or texture (NIR-T) had a bimodal distribution (Fig. 3), indicating that kernel texture is primarily controlled by one gene. Those findings concur with previous studies (Anjum and Walker 1991; Giroux and Morris 1998). As described below, the set of samples under study displayed a similar range in trait data compared with those found in US wheat breeding programs and other studies. Consequently, the genetic correlation (GCOR) results can be held with a greater degree of confidence than conclusions drawn from studies focused on only a few samples or samples with little trait variation.

The mean across all RIL and environments for the image analysis traits were 0.73, 19.6, 21.0, 6.7, 3.9 and $0.59 \mathrm{~mm}$ for SF, PERM, AREA, LEN, WID and DF, respectively. For TW, TKW and NIR-T, the grand means were $800 \mathrm{~kg} / \mathrm{m}^{3}, 35 \mathrm{~g}$ and 39 , respectively. It was difficult to evaluate how representative the variation in some of the kernel traits was of Triticum aestivum germplasm, since reports on wheat kernel morphology variation could be found only for LEN, TW and TKW. However, transgressive segregates, that is, genotypes significantly outside of the range of the parental means were found for nearly all traits. Exceptions were density factor (DF) at the high level and test weight (TW) at the low level. Therefore, sufficient genetic recombination occurred and linkage groups, previously established in US hard and soft wheat germplasm, were broken up. This is an indication that the conclusions drawn from the genetic correlation analysis in this study are valid.

Kernel length (LEN) ranged from a line mean value of 6.4 to $7.2 \mathrm{~mm}$ (Fig. 2). Across all samples it ranged from 6.1 to $7.6 \mathrm{~mm}$. Giura and Saulescu (1996) reported that most cultivars range from 6 to $7 \mathrm{~mm}$ in LEN.

TW line mean values ranged from 762 to $839 \mathrm{~kg} / \mathrm{m}^{3}$ (Fig. 3). Across all samples, the minimum and maximum TW were 697 and $852 \mathrm{~kg} / \mathrm{m}^{3}$, respectively. Historical data, including hundreds of cultivars and early generation breeding lines from the USDA, ARS, Soft Wheat Quality Laboratory (SWQL) for TW, using aspirated samples, have ranged from 785 to $849 \mathrm{~kg} / \mathrm{m}^{3}$. Therefore, the samples in the present study had a range in TW close to that previously recorded for US wheat germplasm.

The range in values for line mean TKW was 30 to $41 \mathrm{~g}$ (Fig. 3) while the grand mean for the population was $35 \mathrm{~g}$. Across all samples, TKW ranged from 27 to $44 \mathrm{~g}$. 

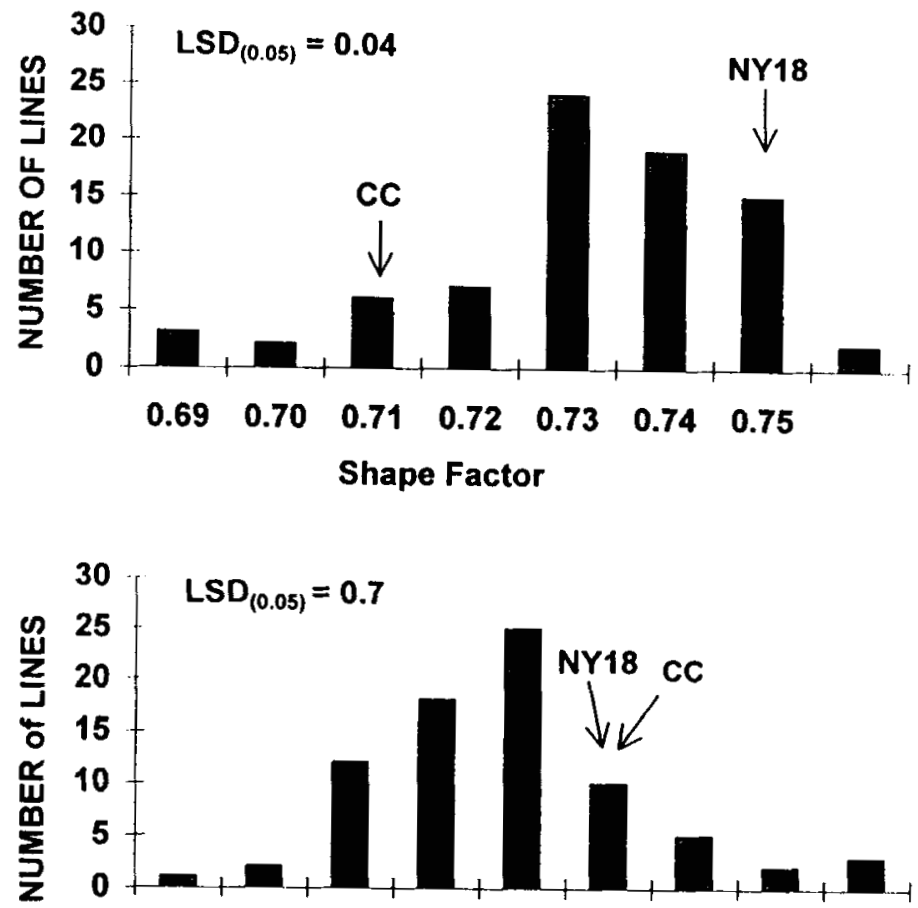

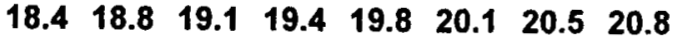

Perimeter (mm)

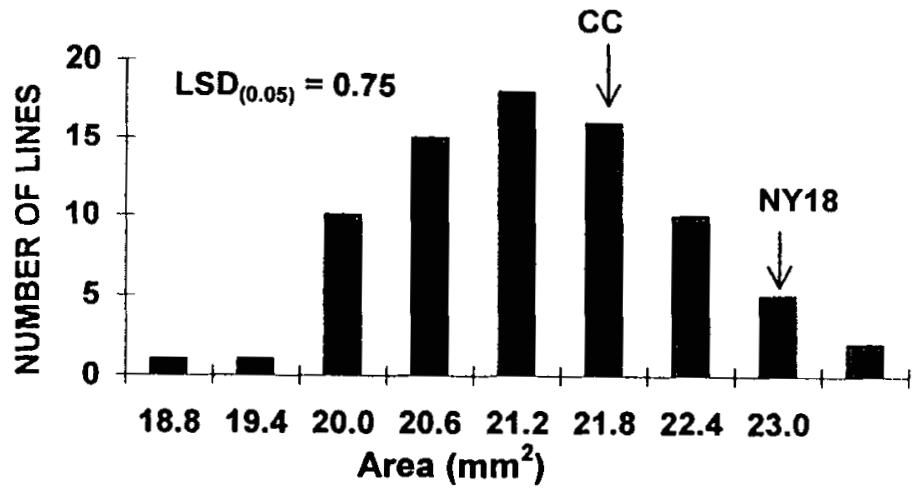

FIG. 1. HISTOGRAM OF KERNEL MORPHOLOGICAL TRAIT (SHAPE FACTOR, PERIMETER AND AREA) VALUES, FOR LINES DERIVED FROM A CROSS BETWEEN A SOFT AND HARD WHEAT

Lines were grown in Ithaca, NY during the 1993 and 1994 crop years. Arrows note mean values for NY18 and CC. A line was included in a category (or represented in a bar) if its trait value was equal to or less than the number under the category down to the previous category number. 

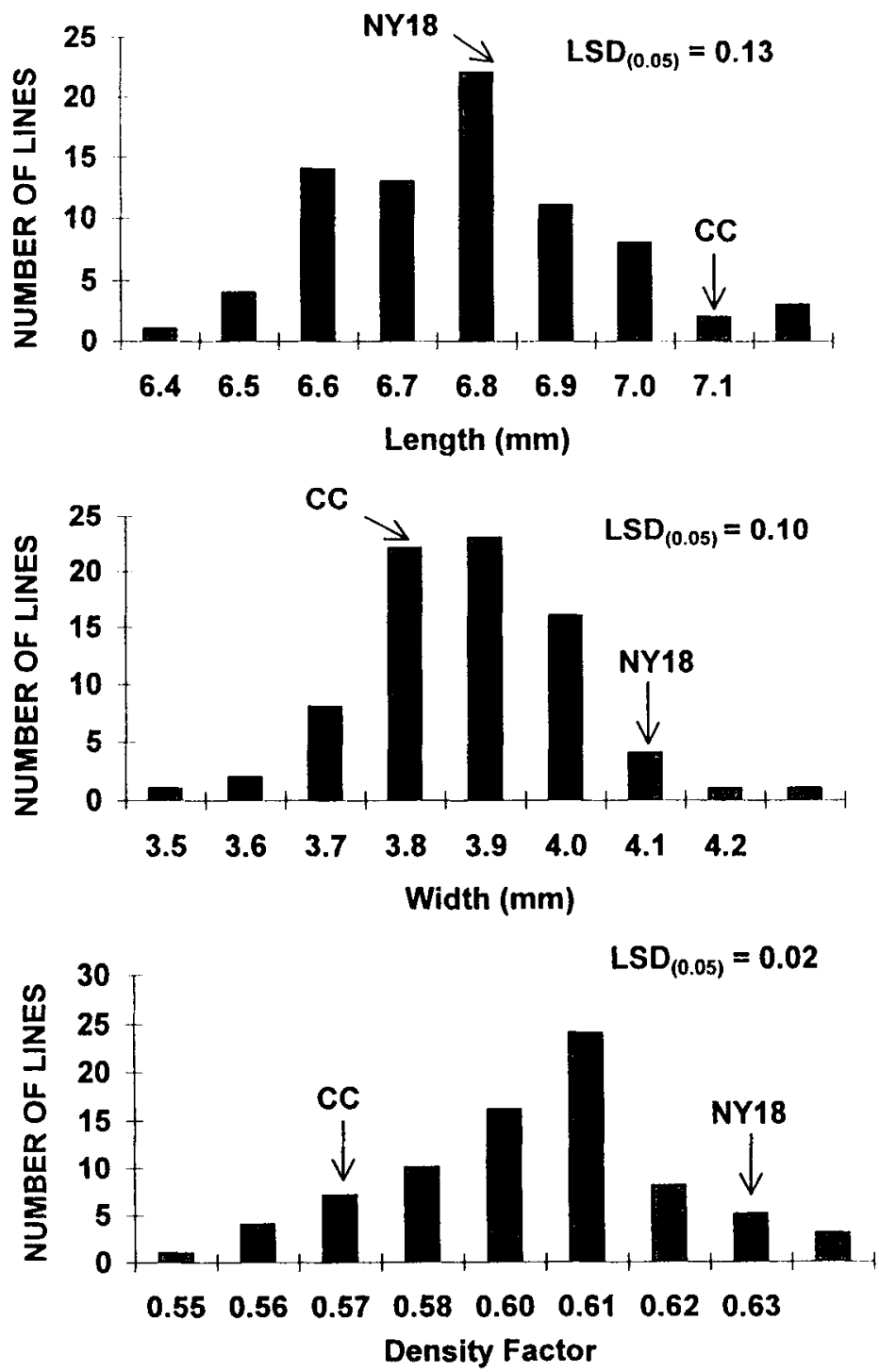

FIG. 2. HISTOGRAM OF KERNEL MORPHOLOGICAL TRAIT (LENGTH, WIDTH AND DENSITY FACTOR) VALUES, FOR LINES DERIVED FROM A CROSS BETWEEN A SOFT AND HARD WHEAT

Lines were grown in Ithaca, NY during the 1993 and 1994 crop years. Arrows note mean values for NY18 and CC. A line was included in a category (or represented in a bar) if its trait value was equal to or less than the number under the category down to the previous category number. 

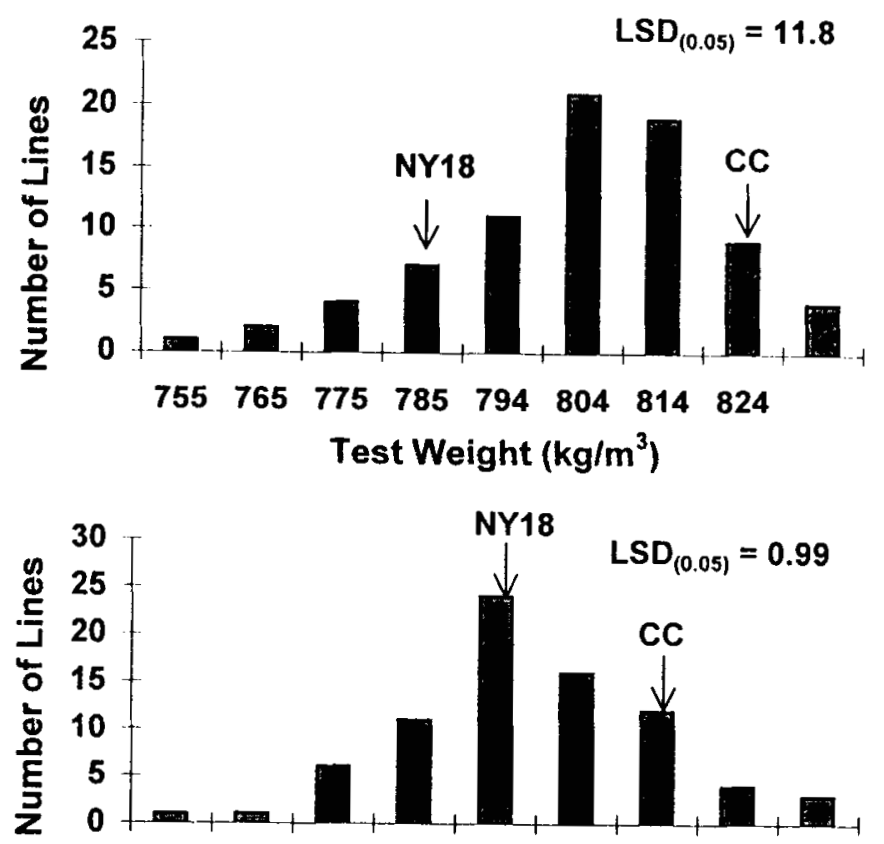

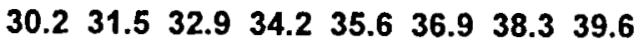

Thousand Kernel Weight (g)

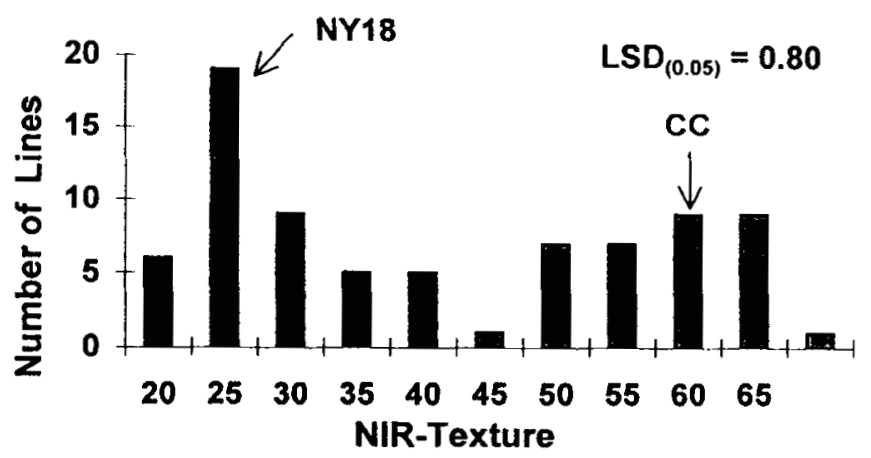

FIG. 3. HISTOGRAM OF KERNEL TEXTURE AS MEASURED BY NEAR-INFRARED REFLECTANCE SPECTROSCOPY (NIR-T), TEST WEIGHT AND THOUSAND KERNEL WEIGHT VALUES, FOR LINES DERIVED FROM A CROSS BETWEEN A SOFT AND HARD WHEAT

Lines were grown in Ithaca, NY. Values for NIR-T are from the 1992, 1993 and 1994 crop years while TW and TKW were determined on the 1993 and 1994 samples. Arrows note mean values for NY18 and $\mathrm{CC}$. A line was included in a category (or represented in a bar) if its trait value was equal to or less than the number under the category down to the previous category number. 
TKW means for NY18 and CC were 36 and $38 \mathrm{~g}$, respectively. Data collected from soft and hard wheat cultivars and early generation lines at the SWQL show TKW values ranging from 10 to $50 \mathrm{~g}$. However, some genotypes with genetically large kernels, such as Stephens, consistently have TKW values of nearly $60 \mathrm{~g}$. Although, in the present study, the range in TKW $(11 \mathrm{~g})$ for the RILs was less than that formerly recorded at the SWQL, it was a substantially greater range than previously reported $(3 \mathrm{~g})$ to be sufficient for performing a reliable genetic analysis of that trait (Halloran 1976).

The relative contribution of each source of variance to total variance for NIR-T, TW and TKW are displayed in Fig. 4. Significant effects of genotype (G), environment $(E)$, and genotype $x$ environment interactions (GXE) were found for all three traits. Genotype contributed the largest source of variation for NIR-T and TKW. The largest source of variation for TW was year. GXE interaction added no more than $10 \%$ of the variation for any trait. None of the Kruskal-Wallis k-sample tests were significant, indicating that those interactions were primarily due to the degree of difference between lines, not due to changes in how they ranked.

Although shriveled kernels were removed during the cleaning process, environmental effects were significant for NIR-T, TW and TKW. Similar results have been reported for TW and TKW in soft red winter wheat grown in multiple locations (Schuler et al. 1995). Therefore, the effect of environment on TW from causes other than shriveling can be substantial.

The heritability values for the quality traits were all high (Table 1). Ranking of the traits resulted in them falling into three readily apparent groups. NIR-T was in the first group, having the greatest heritability; TW, LEN, WID, TKW and AREA were in the middle group; and PERM, DF and SF were in the least heritable group. Although multiple growing seasons were used for this study, the environmental variation was relatively low since all locations were relatively close to one another. The absolute value of the kernel trait heritability estimates would be expected to change with the addition of more diverse environments, but the heritability rankings would likely remain the same.

While simple correlation analysis determines the degree of linear phenotypic association between two traits due to both genetic and environmental effects, genetic correlation analysis removes the effects of the environment. Genetic correlations result from pleiotropy, linked genes or epistasis (Falconer 1989).

The GCOR between LEN and WID was low (Table 2). Those traits are thus apparently inherited independently of each other. Similar findings have been reported for oat morphology (Murphy and Frey 1962; Koeyer et al. 1993). Genetic correlations between NIR-T and LEN, and WID were also low. In the US, hard wheat kernels tend to be longer and narrower than soft wheat kernels. NY18 and $\mathrm{CC}$ followed that trend. However, GCOR analyses provided evidence that LEN and WID, as well as NIR-T and LEN, or WID were independent traits. Hence, the genetic potential exists for developing cultivars having all possible combinations 
90

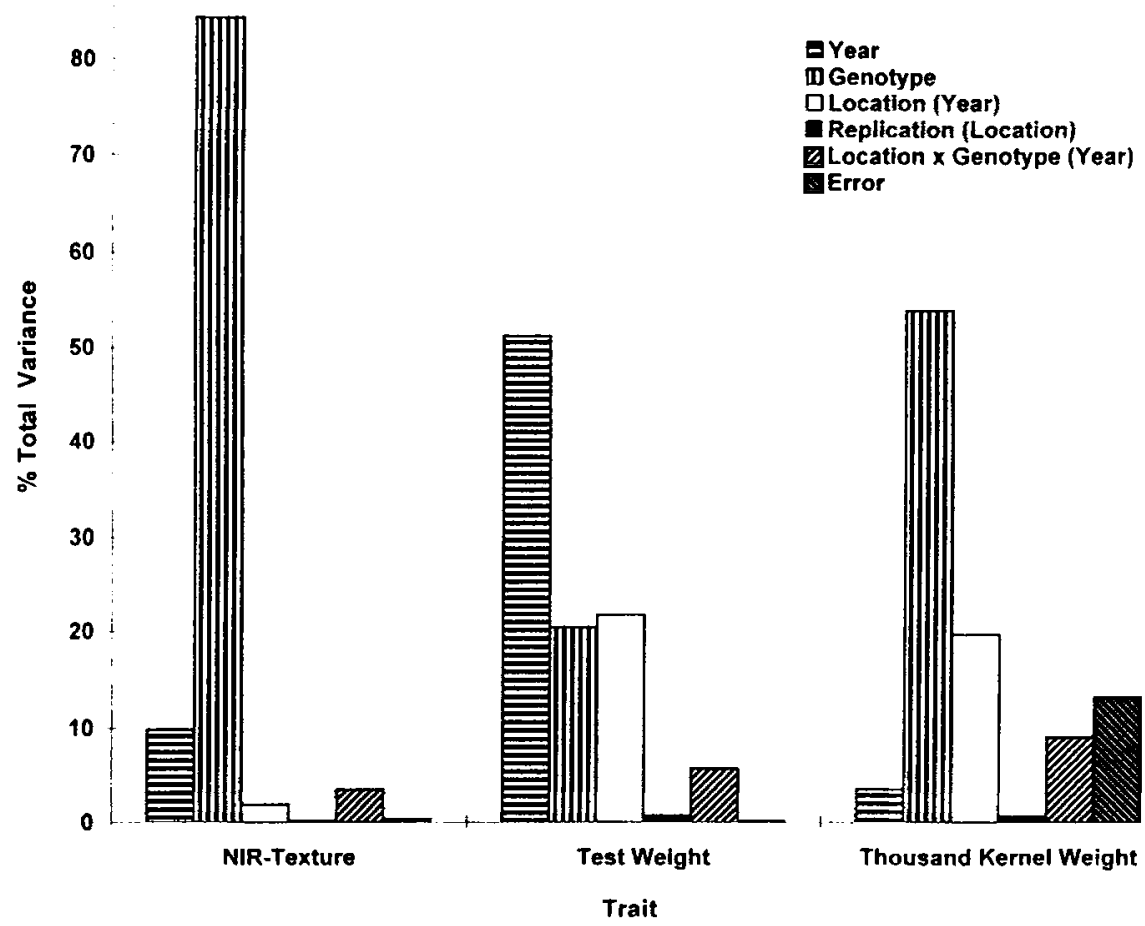

FIG. 4. VARIANCE COMPONENTS FOR KERNEL TRAITS (NIR-TEXTURE, TEST WEIGHT AND THOUSAND KERNEL WEIGHT) AS A PERCENTAGE OF TOTAL VARIANCE, ON AN ENTRY MEAN BASIS DETERMINED FOR A POPULATION DERIVED FROM A SOFT BY HARD WHEAT

Lines were grown in Ithaca, NY during the 1992-1994 crop years.

TABLE 1.

KERNEL TRAIT HERITABILITIES ${ }^{1}$

\begin{tabular}{lccc}
\hline Kernel Trait & Heritabilities & LCL $^{2}$ & UCL $^{3}$ \\
\hline NIR-T & 0.98 & 0.97 & 0.98 \\
TW $\left(\mathrm{kg} / \mathrm{m}^{3}\right)$ & 0.91 & 0.88 & 0.94 \\
LEN $(\mathrm{mm})$ & 0.90 & 0.87 & 0.93 \\
WID $(\mathrm{mm})$ & 0.88 & 0.84 & 0.91 \\
AREA $\left(\mathrm{mm}^{3}\right)$ & 0.87 & 0.84 & 0.90 \\
TKW $(\mathrm{g})$ & 0.87 & 0.82 & 0.90 \\
PERM $(\mathrm{mm})$ & 0.80 & 0.74 & 0.85 \\
DF & 0.78 & 0.70 & 0.84 \\
SF & 0.75 & 0.68 & 0.81 \\
\hline
\end{tabular}

'NIR-T = kemel texture, as measured by near-infrared reflectance spectroscopy. TW $=$ test weight, LEN = kernel length, WID = width, TKW = thousand kernel weight, PERM = perimeter, DF = density factor, and $\mathrm{SF}=$ shape factor.

${ }^{2} \mathrm{LCL}=$ Heritability lower confidence level.

${ }^{3} \mathrm{UCL}=$ Heritability upper confidence level. 


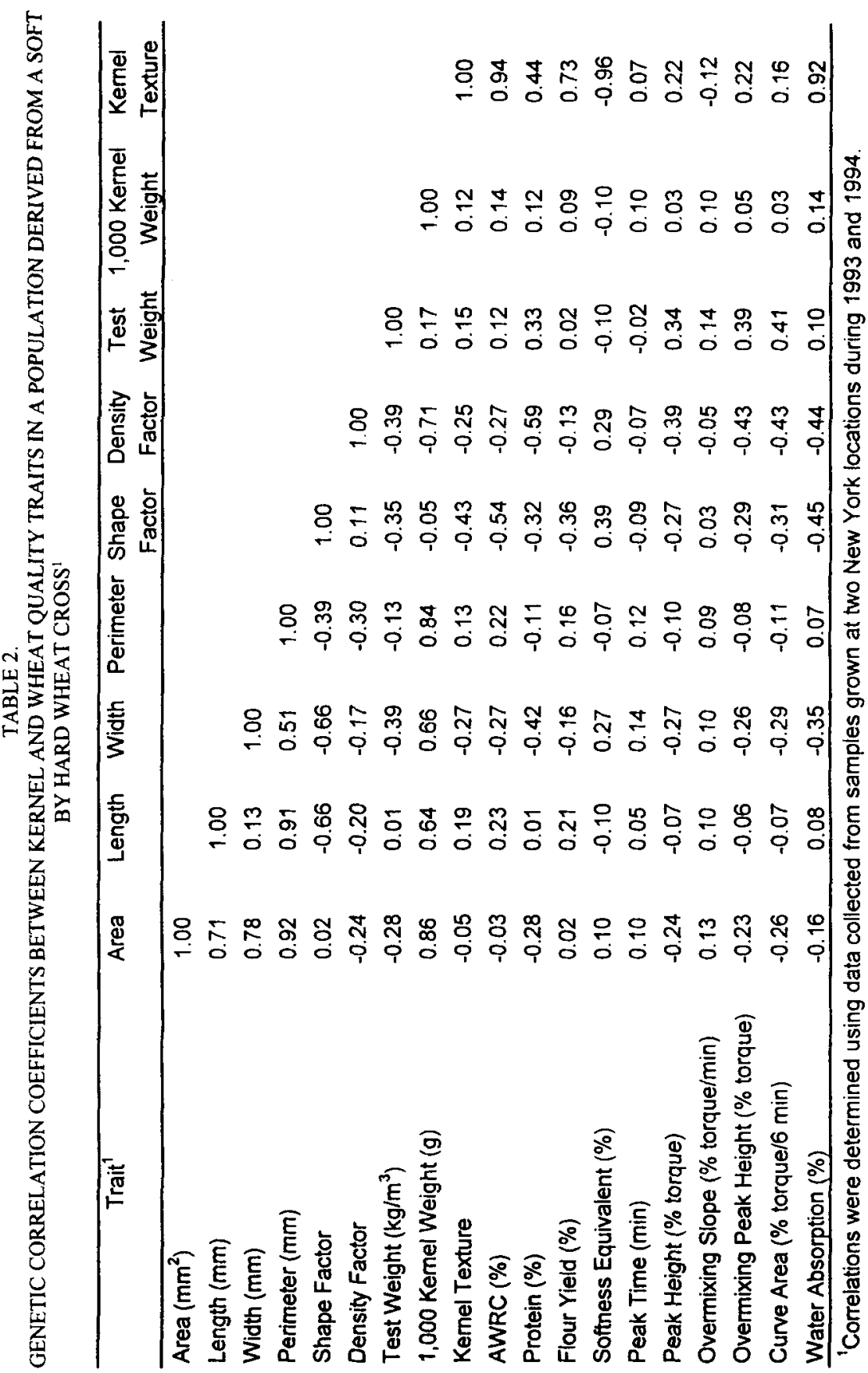


of kernel texture, LEN and WID. Evidently, the associations in US germplasm between kernel texture and morphology have resulted from selection pressure being placed on those traits. AREA was genetically equally associated with LEN $\left(r_{g}=\right.$ $0.71)$ and WID $\left(r_{g}=0.78\right)$. Thus, increased AREA (i.e., larger kernels) can be obtained as efficiently by breeding for longer kernels as well as wider ones.

In the present study, TW was not associated with any of the image analysis traits to any meaningful degree. That indicates that the genetic potential exists for breeding genotypes with high TW and any combination of WID and LEN. TW was also not correlated with NIR-T or TKW. Genetic correlation between TW and DF was $r_{g}=-0.39$. Some have assumed that kernel density influences TW. However, studies have reported low phenotypic correlations between those traits (Ghaderi and Everson 1971; Ghaderi et al. 1971). Other studies have suggested that variation in TW is primarily related to differences in WID, kernel thickness, LEN to WID ratio and kernel packing efficiency (Shuey 1960; Merkle et al. 1969; Ghaderi et al. 1971), while some have reported low to no association between kernel morphological traits and TW (Yamazaki and Briggle 1969; Schuler et al. 1994). These apparent conflicting conclusions may be a consequence of the samples analyzed by each group having very different degrees of trait variation. Examining traits in only a few genotypes can result in conclusions about trait associations that are phenotypically true for those genotypes but not necessarily true for wheat germplasm at large.

Test weight had no more than a weak association with any of the MBQ traits previously reported for this population by Bergnian et al. (1998), both across or within the texture classes (Table 2). For example, there was no relationship between TW and FY either across or within the soft or hard wheat texture classes. Finney and Bergman (1994), studying over 500 cultivars and breeding lines, reported similar findings. The present study provides the wheat industry further evidence that TW is unable to reliably predict FY or other aspects of end-use quality. Consequently, a rapid test able to accurately predict $F Y$ is needed.

TW and PRO were not genetically correlated with each other across all samples or within a texture class. Finney and Bergman (1994) also reported a lack of correlation between those two traits in a large group of soft wheats. On the contrary, Yamazaki and Briggle (1969) reported that soft wheat TW values were lower than hard wheat values due to the lower inherent protein content of that class. Examining 24 cultivars, Schuler et al. (1994) reported TW and PRO to be correlated. These conflicting reports may be a result of the differences in the samples that were studied. The studies using samples with a great deal of genotypic and environmental variation found no association between TW and PRO. On the contrary, those who studied just a few varieties reported significant associations between TW and PRO. Thus, reports of an association between TW and PRO may have resulted from chance stemming from the small number of samples chosen for study. 
Across genotypes, no relationship existed between TKW and FY in the present study. Although previous reports have suggested that TKW had the potential to replace TW as a predictor of FY potential, others have indicated that there was no relationship between those traits (Shuey 1960; Johnson and Hartsing 1963; Hook 1984). From the present study it appears that TKW would not be a suitable predictor of FY.

DF was genetically correlated with PRO $\left(r_{g}=-0.59\right)$ and also with TKW $\left(r_{g}=\right.$ - 0.71). But PRO and TKW were not associated, thus suggesting that some component besides PRO, which also influences kernel density, created the association between DF and TKW. Others have reported similar phenotypic correlations between kernel density and PRO, but not between kernel density and TKW (Yamazaki and Briggle 1969; Schuler et al. 1995).

Soft wheat product texture (e.g., cookies and cakes) phenotypically correlates with kernel texture (Gaines et al. 1992a, b). Kernel texture has been quantified using various methods such as work to grind, time to grind, average particle size of the flour and NIR-T. Softness equivalent (SE) is the method used to assess kernel texture of breeding lines and varieties at the SWQL. Essentially, SE is the quantity of flour produced from the first break during milling. Near-infrared technology predictions of texture could be very useful to a quality evaluation program because the method requires small sample size and is relatively quick. As a direct measure of kernel texture, $\mathrm{SE}$ is suitable for evaluating NIR-T prediction accuracy. In the present study, the GCOR between NIR-T and SE was $r_{g}=-0.96$ (Table 2). No previous reports of the association between SE and NIR-T could be found. However, Pomeranz and Afework (1984) reported that another direct measure of kernel texture, particle size index, was also phenotypically correlated $(r=0.90)$ with NIR-T. Clearly, SE and NIR-T are measures, at least in part, of the effects of the same gene(s) and its interactions.

Across the hard textured lines (i.e., NIR-T $>36$ ), the association between NIR-T and SE was similar in magnitude $(r=-0.81)$ to that across the entire population. Contrarily, however, across the soft textured lines (i.e., NIR-T<36) the correlation was much lower $(r=-0.55)$. Therefore, NIR-T was not correlated with SE at a high enough level to be considered a reliable predictor of texture for soft wheat breeding programs. Those results indicate that caution should be taken when considering using a predictive test within a grain class, when it has only been studied across classes.

None of the kernel traits measured by image analysis correlated well with FY in the present study. No phenotypic correlations between FY and LEN, WID or their ratio were found by Schuler et al. (1995), while Berman et al. (1996) found associations (adjusted $R^{2}=66 \%$ ) between FY and kernel traits using advanced lines and cultivars. Based on that association, Berman et al. (1996) suggested that image analysis of grain morphology would be an acceptable predictor of FY in breeding programs. Because image analysis would not have worked in the population 
currently being discussed, it appears that some other predictive test for FY is needed to assist breeders in the screening process during cultivar development. Future studies focused on that goal might include an examination of the association between FY and other morphological traits such as bran thickness, crease depth and aleurone layer thickness.

In the present study, NIR-T had a high GCOR with FY across all lines $\left(r_{g}=\right.$ 0.73 , respectively). Bassett et al. (1989) reported high phenotypic associations between FY and SE for soft wheat cultivars grown in many locations. The association between measures of kernel texture and FY suggests that the $\mathrm{Ha}$ gene, located on chromosome $5 \mathrm{D}$, which controls wheat texture either also influences FY or harder wheats simply mill more efficiently (Anjum and Walker 1991). Either way, it is apparent that soft wheat breeders have an opportunity to increase FY by making soft by hard wheat crosses.

\section{CONCLUSION}

This study provides breeders an understanding of the potential variation in kernel morphology traits that may result from a soft by hard wheat cross and the associations amongst kernel morphology and end-use quality traits that can be expected. For example, the genetic potential appears to exist for developing cultivars possessing all variations of kernel texture, kernel length and kernel width. That is, new hard wheat cultivars do not have to be long and thin, nor do soft wheats have to be short and round, as has historically been the case for US cultivars. With such knowledge the food industry may find applications suited for wheat possessing grain shape and texture combinations other than those previously available. This study also found that FY was not genetically associated with kernel morphology traits or with TW, thus indicating that breeding lines should continue to be screened for their FY potential using a micro milling test until a more reliable predictor of FY is developed. The low correlations found among some traits in the current study disagree with the findings of some previous studies that were focused on either soft or hard wheats. Thus, further efforts may be needed to clarify the relationships between wheat kernel morphology and end-use quality traits.

\section{REFERENCES}

AACC.1995. Official Methods of Analysis, 9th Ed. American Association of Cereal Chemists, Saint Paul, MN.

ANDERSON, J.A., SORRELLS, M.E. and TANKSLEY, S.D. 1993. RFLP analysis of genomic regions associated with resistance to preharvest sprouting in wheat. Crop Sci. 33, 453-459. 
ANJUM, F.M. and WALKER, C.E. 1991. Review on the significance of starch and protein to wheat kernel hardness. J. Sci. Food Agric. 56, 1-13.

BASSETT, L.M., ALLAN, R.E. and RUBENTHALER, G.L.1989. Genotype $x$ environment interactions on soft white winter wheat quality. Agron. J. 81 , 955-960.

BERGMAN, C.J., GUALBERTO, D.G., CAMPBELL, K.G., SORRELLS, M.E. and FINNEY, P.L. 1998. Genotype and environment effects on wheat quality traits in a population derived from a soft by hard cross. Cereal Chem. 75, 729-737.

BERMAN, M., BASON, M.L., ELLISON, F., PEDEN, G. and WRIGLEY, C.W. 1996. Image analysis of whole grains to screen for flour-milling yield in wheat breeding. Cereal Chem. 73, 323-327.

BRIGGLE, L.W., YAMAZAKI, W.T. and HANSON, W.D. 1968. Heritability of three soft wheat quality characters in the $\mathrm{F}_{2}$ and $\mathrm{F}_{3}$ generations. Crop Sci. 8, 283-285.

DAVIS, W.H., MIDDLETON, G.K. and JEBERT, T.T. 1960. Inheritance of protein, texture, and yield in wheat. Theor. Appl. Genet. 1, 235-238.

DEKOEYER, D.L., STUTHMAN, D.D., FULCHER, R.G. and POMERANKE, G.J. 1993. Effects of recurrent selection for grain yield on oat kernel morphology. Crop Sci. 33, 924-928.

EVERS, A.D. and STEVENS, D.J. 1985. Starch damage. In Advances in Cereal Science and Technology, Vol. VII, (Y. Pomeranz, ed.) pp. 321-349, Am. Assoc. Cereal Chem., Saint Paul, MN.

FALCONER, D.S. 1989. Introduction to Quantitative Genetics, 2nd Ed., p. 340, John Wiley \& Sons, New York.

FINNEY, P.L. and BERGMAN, C.J. 1994. Test weight in relation to various milling and baking properties of eastern US soft wheats. In Proceedings of the Regional Quality Symposium for Soft Red Winter Wheat, September 7-8, pp. 40-66, Arkansas Press, Little Rock, AR.

GAINES, C.S., KASSUBA, A. and FINNEY, P.L. 1992a. Instrumental measurement of cookie hardness. I. Assessment of methods. Cereal Chem. 69, 115-119.

GAINES, C.S., KASSUBA, A., FINNEY, P.L. and DONELSON, J.R. 1992 b. Instrumental measurement of cookie harness. II. Application to product quality variables. Cereal Chem. 69, 120-125.

GHADERI, A. and EVERSON, E.H. 1971. Genotype-environment studies of test weight and its components in soft winter wheat. Crop Sci. 11, 617-620.

GHADERI, A., EVERSON, E.H. and YAMAZAKI, W.T. 1971. Test weight in relation to the physical and quality characteristics of soft winter wheat. Crop Sci. $11,515-518$. 
GIROUX, M. and MORRIS, C.F. 1998. Wheat grain hardness results from highly conserved mutations in the friabilin components puroindline $\mathbf{a}$ and $\mathbf{b}$. Proc. Natl. Acad. Sci. USA. 95, 6262-6266.

GIPSA, 1997. Subpart M. Wheat. In Official United States Standards for Grain Inspection. United States Department of Agriculture Grain Inspection, Packers and Stockyards, Administration. Washington, DC.

GIURA, A. and SAULESCU, N.N. 1996. Chromosomal location of genes controlling grain size in a large grained selection of wheat (Triticum aestivum L.). Euphytica 89, 77-80.

HALLORAN, G.M. 1976. Genetic analysis of hexaploid wheat, Triticum aestivum using intervarietal chromosome substitution lines - protein content and grain weight. Euphytica 25, 65-71.

HOOK, S.C.W. 1984. Specific weight and wheat quality. J. Sci. Food Agric. 35, 1136-1141.

JOHNSON, R.M. and HARTSING, T.F. 1963. Kernel count as a measure of flour milling yield. Northwest Miller 269, 22-26.

KNAPP, S.J., STROUP, W.W. and ROSS, W.M. 1985. Exact confidence intervals for heritability on a progeny mean basis. Crop Sci. 25, 192-194.

KOEYER, D.L., STUTHMAN, R.G., FULCHER, R.G. and POMERANKE, G.J. 1993. Effects of recurrent selection for grain yield on oat kernel morphology. Crop Sci. 33, 924-928.

LOFGREN, J.R., FINNEY, K.F., HEYNE, E.G., BOLTE, L.E., HOSENEY, R.C. and SHOGREN, M.D. 1968. Heritability estimates of protein content and certain quality and agronomic properties in bread wheat (Triticum aestivum L.). Crop Sci. 8, 563-568.

MARSHALL, D.R., MARES, D.J., MOSS, H.J. and ELLISON, F.W. 1986. Effects of grain shape and size on milling yields in wheat. II. Experimental studies. Aust. J. Agric. Res. 35, 619-630.

MERKLE, O.G., ATKINS, I.M. and ISLAM, T-UL. 1969. Relationship of certain kernel characteristics to test weight in wheat. In Consolidated Report no. $P R-2657-2660$, pp. 3-6, Texas Agric. Expt. Sta. College Station, Texas.

MURPHY, C.F. and FREY, K.J. 1962. Inheritance and heritability of seed weight and its components in oats. Crop Sci. 2, 509-512.

POMERANZ, Y. and AFEWORK, S. 1984. The effects of kernel size in plump and shrunken kernels, and of sprouting, on kernel hardness in wheat. J. Cereal Sci. 2, 119-126.

ROUSSET, M., CARRILLO, J.M., QUALSET, C.O. and KASARDA, D.D. 1992. Use of recombinant inbred lines of wheat for study of associations of high-molecular-weight glutenin subunit alleles to quantitative traits. 2. Milling and bread-baking quality. Theor. Appl. Genet. 83, 403-412. 
SCHULER, S.F., BACON, R.K., FINNEY, P.L. and GBUR, E.E. 1995. Relationship of test weight and kernel properties to milling and baking quality in soft red winter wheat. Crop Sci. 35, 949-953.

SCHULER, S.F., BACON, R.K. and GBUR, E.E. 1994. Kernel and spike character influence on test weight of soft red winter wheat. Crop Sci. 34, 1309-1313.

SHUEY, W.C. 1960. A wheat sizing technique for predicting flour milling yield. Cereal Sci. Today 5, 71-72,75.

SAS Institute (Statistical Analysis System). 1988. SAS Users Guide. Statistics. SAS Inst., Cary, NC.

YAMAZAKI, W.T. and BRIGGLE, L.W. 1969. Components of test weight in soft wheat. Crop Sci. 9, 457-459. 